\title{
Performance of Different Substrates on Growth Parameters of (Pleurotus ostreatus) Mushroom
}

\author{
Victor C. Wabali and Obisie Favour
}

\section{ABSTRACT}

Pleurotus ostreatus mushroom was cultivated on sawdust supplemented with different substrates, Cassava peel, Yam peel, and dried plantain leaf. Various treatment combinations of control, $2.5 \%, 5.0 \%, 7.5 \%, 10.0 \%$, $12.5 \%, 15.0 \%$ and $17.5 \%$ carried out. Preparation of spawn, inoculation, incubation, and harvesting were done. Growth parameters of mean height, weight, diameter of fruiting bodies, mean stem girth and number of fruiting bodies were evaluated. Results showed that sawdust supplemented at $10 \%$ treatment level with Cassava peel was significantly higher than substrates in weight $(229.34 \mathrm{~g})$, height $(95.01 \mathrm{~cm})$ and number of fruiting bodies (103.21).

Keywords: Pleurotus ostreatus, Mushroom, Substrates, Cultivation, Growth parameters.

\author{
Submitted : March 17, 2021 \\ Published : April 24, 2021 \\ ISSN: 2684-1827 \\ DOI: $10.24018 /$ ejfood.2021.3.2.265 \\ Victor C. Wabali * \\ Department of crop/soil science, Faculty \\ of agriculture, University of Port \\ Harcourt, Nigeria. \\ (e-mail: victor.wabali@ ${ }^{@}$ uniport.edu.ng) \\ Obisie Favour \\ Department of crop/soil science, Faculty \\ of agriculture, University of Port \\ Harcourt, Nigeria. \\ *Corresponding Author
}

\section{INTRODUCTION}

The Provision of affordable and available food to meet the growing world population constitutes one of the major challenges of this century. The growth of the world population to over 9 billion entails an increase in the production of food to meet the existing demand. There is an urgent need to curb hunger and food scarcity especially in Africa and developing countries [1]. Malnutrition is a problem in third world countries and mushroom with their flavour, texture, nutritional value, and high productivity per unit area have been identified as an excellent food source to alleviate malnutrition. Mushroom cultivation portends a viable option to alleviate hunger, poverty and enhance the lifestyle of vulnerable people by becoming a veritable vehicle for employment. Mushrooms constitute a rich source of nutrient in the diet, being low in calories and fat but rich in proteins and chitin. They contain appreciable amounts of dietary fiber and contain vitamins such as niacin, riboflavin, vitamin $\mathrm{D}, \mathrm{C}, \mathrm{B}_{5}$ [2], [3]. The role of mushrooms in nutritional enhancement of individual wellbeing is important as mushrooms are known to solve dietary related health problems [4]. Pleurotus ostreatus mushrooms are known to have multiple medicinal properties such as cardiovascular and cholesterol controlling beneficial effects. Other benefits include anti-inflammatory, anti-viral, and also shown effectiveness as anti-cancer agent [5]-[7]. According to Tangiuchi [8], there are four major uses of mushrooms namely, industrial, food, pharmaceutical, physiology and biotechnology. However, the nutritional content of mushrooms varies depending on the variety of mushroom and the substrate upon which they are cultivated [9]. The availability of edible mushroom during a specific time in its natural habitat, limit the use of mushroom. An effective utilization can be achieved by cultivation of mushroom using different substrates. Such cultivation will provide availability throughout the year round rather than seasonal availability.

Despite its nutritional value, mushroom cultivation is not widespread as most of the mushrooms consumed are grown in the wild. The composition of the substrate constitutes a major factor in the determination of mushroom yield and output. Therefore, the evaluation of different agricultural substrates to determine to the effect on yield of mushroom is a primary direction of this research work. Improved yield will enhance mushroom availability while providing employment and financial gains to the mushroom farmer. Many types of mushrooms exist, both edible and inedible. Some of the species found in Nigeria are Pleurotus, Volvariella, and Tricholoma [10]. Mushrooms are saprophytes and they are capable of decomposing organic matter. Most agricultural wastes used in the cultivation of mushrooms are resistant to degradation as a result of the presence of hemicellulose, lignin, and celluloses. However, fungal enzymes degrade these substances and convert to simpler molecules which are utilized for growth. Pleurotus ostreatus performs better in a substrate composition of low nitrogen content. The amount of nutrient in a substrate affects the formation of fruiting bodies [11]. In nature, mushrooms use spores for generative multiplication, and these are microscopic and difficult to handle. Alternatively, tissue culture taken from cap tissues may be used to prepare spawn. As time progresses the mycelium grows through the grain. The spawn which is the fully colonised grain is used 
to seed already prepared substrates for mushroom production. A number of spawn grains and substrate medium have been used for mushroom cultivation. Environmental factors such as temperature, oxygen, carbon dioxide, humidity, light, and $\mathrm{Ph}$ have been reported to affect the yield of mushroom [12], [13]. The nutrient composition of substrates plays a key role in the vegetative and fruit body formation of mushroom. Therefore, the evaluation of different substrates to determine their effect on yield and growth parameters is a major direction of this research.

\section{MATERIALS AND METHODS}

Cassava peel, Yam peel, and dried Plantain leaves were used as supplements to sawdust in the cultivation of Mushroom (Pleurotus ostreatus). The various substrates excluding sawdust were sundried for 7 days to reduce moisture content and sorted to remove extraneous material. Particle size reduction operations was carried out for cassava and yam peel substrates by milling while dried plantain leaves were shredded into smaller pieces. The various substrates (Cassava peel, yam peel and dried plantain leaves) were each mixed with sawdust at 8 different treatment levels of control, $2.5 \%, 5.0 \%, 7.5 \%, 10.0 \%$, $12.5 \%, 15.0 \%$ and $17.5 \%$. Then, each treatment was carried out in triplicates. $2 \mathrm{~kg}$ of each treatment was bagged in a white plastic bag tightly tied with plastic rings and sterilized in a drum for four hours to destroy microbial contamination and allowed to cool. And the cooled bags were inoculated with Pleurotus ostreatus spawn under a laminar flow. The bags were thereafter incubated in the incubation room for 30 days to attain full mycelium colonization. The temperature range was maintained at $26-30{ }^{\circ} \mathrm{C}$. At the expiration of the 30 day period the bags were transferred to the fruiting room.

\section{DATA COLLECTION}

Data was collected from the different substrates in triplicates and mean values obtained. Growth parameters of the mushroom on the different substrates were measured as follows:

Height of fruiting bodies: The height was measured in centimetres using a ruler from the base of the stripe to the pileus.

Number of fruiting bodies: The number of fruiting bodies was done by counting directly the fruiting bodies on each substrate bag.

Diameter of Pileus: Diameter of pileus was determined with a ruler. Measurement was carried out from one edge of the pileus across the stripe to the other edge.

Fresh weight of fruit bodies: Measurement of fresh weight of fruit bodies was done with a digital weighing balance. The results obtained were subjected to statistical analysis in a completely randomised design and means were separated by analysis of variance (ANOVA) using SPSS version 18.0.

\section{RESUlTS AND DiscUSSION}

Results of the mean fresh weight of harvested mushrooms are shown in Fig. 1. The results indicated that mushrooms grown on $10 \%$ cassava peel and $90 \%$ wood sawdust were significantly higher with a value of $229.34 \mathrm{~g}$ than the control containing wood sawdust $(158.98 \mathrm{~g})$. The results also showed decreasing values of weight yield with increase in substitution levels with cassava from $12.5 \%$ to $17.5 \%$. Results of fresh weight yield for yam peel substrates showed that sawdust was a better substrate for cultivated of mushroom with a value of $152.20 \mathrm{~g}$ which was significantly higher $(\mathrm{p} \geq 0.05)$ than the substrate containing $7.5 \%$ yam peel with a value $148.0 \mathrm{~g}$. Substrates treated with dried plantain leaf did not contribute to the mean weight of the mushrooms.

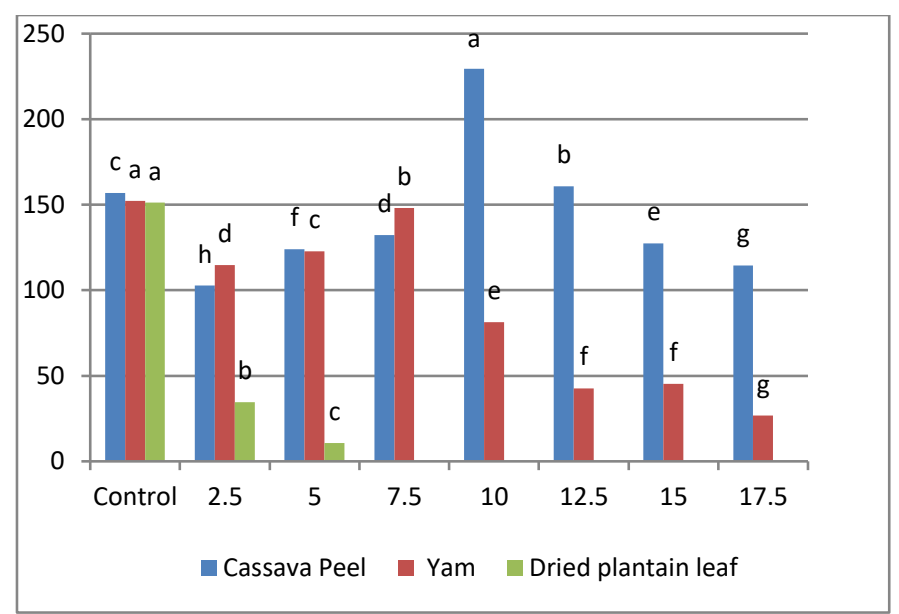

Fig. 1. Mean weight of Mushroom (g). Colour with the same superscript is not significantly different $(\mathrm{p} \leq 0.05)$.

The effect of the various substrate treatments on the height of the mushrooms are shown in Fig. 2. The result for height parameters indicated that substitution of saw dust with $10 \%$ cassava peel showed improved height parameters of $95.01 \mathrm{~cm}$ when compared to the control (sawdust only) $85.37 \mathrm{~cm}$. The result obtained for the yam peel substituted substrates were lower than the control, thereby indicating that sawdust was a better substrate for mushroom growth. The result showed that $7.5 \%$ of yam peel was significantly higher $(\mathrm{p} \geq 0.05)$ than all yam peel substrate treatments with a value of $68.52 \mathrm{~cm}$. Substrate blends containing dried plantain leaf were low with values of $18.56 \mathrm{~cm}$ and $8.35 \mathrm{~cm}$ for $2.5 \%$ and $5 \%$ substrate substitution levels respectively. The results of diameter of fruiting bodies shown in Fig. 3 indicated that $10 \%$ cassava peel and wood sawdust exhibited significantly higher value $103.23 \mathrm{~cm}$ in pileus diameter than the control (sawdust) $69.62 \mathrm{~cm}$ indicating that $10 \%$ cassava peel and $90 \%$ wood sawdust was a better substrate for mushroom cultivation. All the substrates containing yam peel and dried plantain leaf showed significantly lower values of diameter of fruiting bodies when compared to the control. 


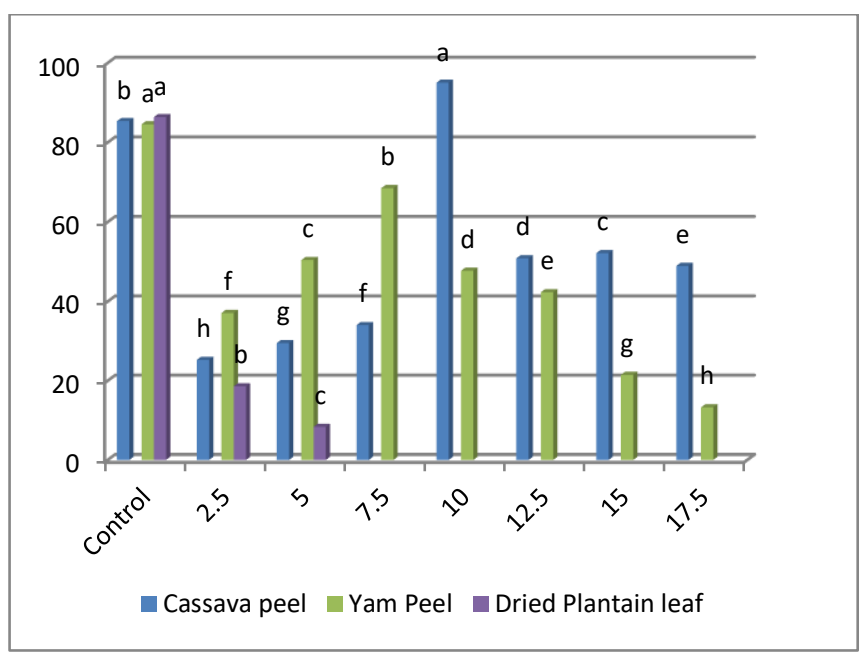

Fig. 2. Mean height of Mushroom (cm). Colours with the same superscript are not significantly different $(\mathrm{p} \leq 0.05)$.

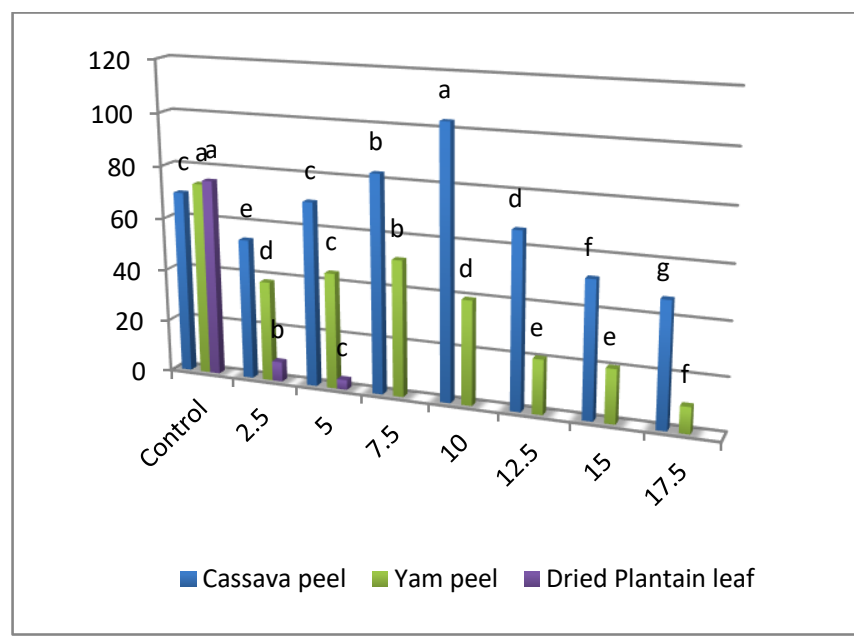

Fig. 3. Diameter of fruiting bodies $(\mathrm{cm})$ colours with the same superscript are not significantly different $(\mathrm{p} \leq 0.05)$.

The result of the mean stem girth in Fig. 4 indicated that the substrate containing $10 \%$ cassava peel did not differ significantly from the control. However, $5-17.5 \%$ of cassava peel substituted substrates performed better than yam peel and dried plantain leaf. Dried plantain leaf did not support stem girth parameters beyond $7.5 \%$ concentration levels. The yam peel stem girth parameters showed that $7.5 \%$ of yam peel concentration in the substrate was significantly higher $(34.65 \mathrm{~cm})$ than all other yam peel values, though lower than the control $(55.74 \mathrm{~cm})$.

The results obtained for Cassava peel treatments which indicated higher values for weight, height, diameter, and number of fruiting bodies are in agreement with Kholoud [14] who reported that supplementation of sawdust with agricultural wastes improved some growth parameters. The improvement in growth parameters may be as a result of the capacity of Pleurotus ostreatus mushroom to produce degrading enzymes complexes which attack and degrade cellulose, hemicelluloses and lignin of plant tissues and consequently using them as nutrients for their growth. Viziteu [15] reported that Pleurotus ostreatus (oyster) mushroom consumes high amounts of cellulose, hemicelluloses and nitrogen for nutritional requirement which contributes to mycelia growth and fruiting bodies formation. Formation of pinheads which constitute the second stage in mycelia growth was observed within 7 days.
This observation was in agreement with [16] and Vetayasuporn [17].

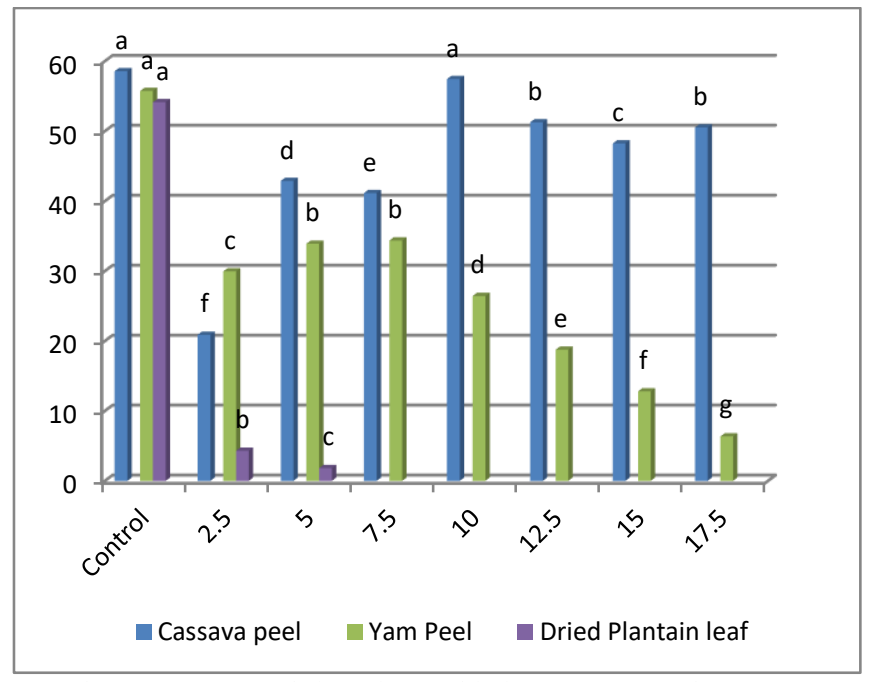

Fig. 4. Mean stem girth: Colours with the same superscript are not significantly different $(\mathrm{p} \leq 0.05)$.

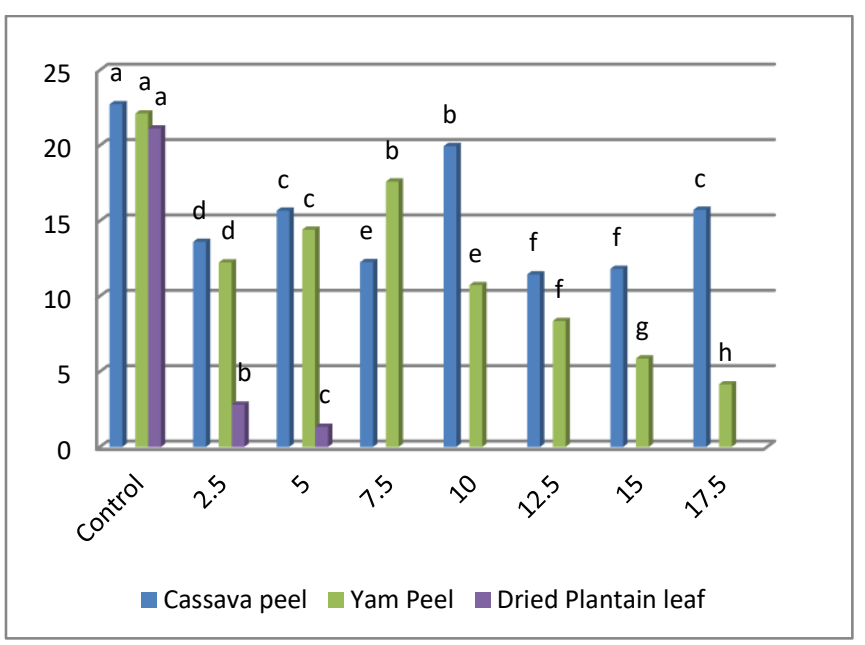

Fig. 5. Mean number of fruits. Colours with the same superscript are not significantly different $(\mathrm{p} \leq 0.05)$.

\section{CONCLUSION}

Mushroom cultivation can be enhanced with the addition of agricultural waste such as Cassava peel. The addition of $10 \%$ Cassava peel to sawdust formulation improved mushroom height, weight, pileus diameter and number of fruiting bodies.

\section{REFERENCES}

[1] Stephanis C. (2014). Global food security: An agricultural perspective. Journal of Agriculture and Sustainability. 6 (1): 69-87.

[2] Chang S.T. and Miles P.G, (1997). Mushroom Biology. 90-96. World Scientific press. Hong Kong.

[3] Manzi P, Marconi S, and Aguzzi A 1999. Nutrients in edible mushroom: An interspecies comparative study. Journal of Food Chem. 65:477-481.

[4] Atikpo M, Abazinge M, Onokpise O, and Boateng L. (2008). Sustainable mushroom production in Africa. African Journal of Biotechnology. 7(3): 249-253.

[5] Jose N, AjithT.A, and Janardhan k. (2002). Antioxidant, antiinflammatory and anti tumour activities of culinary medicinal mushroom, Pleurotus pulmonaries. International Journal of medicinal mushroom 4: 133. 
[6] Gundee- Cimerman N, (1999). Medicinal value of the genus Plerotus. International Journal of medicinal mushroom. 1: 69-80.

[7] Wasser S. and Weis A. (1999). General description of the most important higher basidiomycetes mushroom. International Journal of medicinal mushrooms. 1: 351-370.

[8] Taniguchi M (2000). The Japanese industry mushroom farming. Japan 34: $35-40$.

[9] Ukoima, H.N, Ogbonnaya L., Arikpo G, and Ikpe F.N. (2009). Cultivation of mushrooms (Volvariella volvacea) on various farm wastes in Obubra local government area of Cross River State, Nigeria.

[10] Zoberi H.M. (1972) Tropical maco fungi. pp158. Macmillian London.

[11] Dike K, (2011). Edible mushroom from waste products. Journal of Microbiology Biotech Research 1 (3): 1-14.

[12] Nwanze P, Khan A, Ameh A. U. and Umoh V.J. (2005). The effect of interaction of various spawn grains with different culture medium on Carpophores dry weight, stipe and Pileus diameters of Lentinus squarrosulus. African Journal of Biotechnology. 4: 615-619.

[13] Stamete P. (2000). A novel approach to farm waste mushroom management. Journal of Winter. 4: 22.

[14] Kholoud M, Bouqellah A, Nadia S. (2014). Cultivation of oyster mushroom Pleurotus ostreatus on date -palm leaves mixed with other agro-wastes. Saudi Journal of Biological Sciences. 21(6): 616-625.

[15] Viziteu G. (2000). Substrate - Cereal straw and Corn cobs: In mushroom Growers Handbook. P and F Publishers, U.S.A. pp 86-90.

[16] Shah z., Ashraf M, and Ishtiaq M. (2004). Comparative study on cultivation and yield performance of Oyster mushroom (Pleurotus ostreatus) on different substrates. Paksitan Journal of Nutrition 3: $158-160$.

[17] Vetayasuporn S. (2007). The feasibility of using coconut residue as a substrate for Oyster mushroom cultivation. Biotechnology 6: 578582.

[18] Candy C.I., (1990). The cultivation of Pleurotus in Mauritania. Proceedings of $1^{\text {st }}$ conference on African mycology. Mauritania 1: 1215. 